\title{
Taking Up Offenses: Secondhand Forgiveness and Group Identification
}

\author{
Ryan P. Brown \\ University of Oklahoma \\ Michael J. A. Wohl \\ Carleton University \\ Julie Juola Exline \\ Case Western Reserve University
}

When a person or group is mistreated, those not directly harmed by the transgression might still experience antipathy toward offenders, leading to secondhand forgiveness dynamics similar to those experienced by firsthand victims. Three studies examine the role of social identification in secondhand forgiveness. Study 1 shows that the effects of apologies on secondhand victims are moderated by level of identification with the wronged group. Study 2 shows that identification with the United States was associated with less forgiveness and greater blame and desire for retribution directed at the 9/11 terrorists, and these associations were primarily mediated by anger. Finally, Study 3 shows that participants whose assimilation needs were primed were less forgiving toward the perpetrators of an assault on ingroup members than participants whose differentiation needs were primed, an effect that was mediated by empathy for the victims.

Keywords: forgiveness; identification; empathy; intergroup conflict; apology

$\mathrm{B}$ ad things happen to everyone. Friends miss dates, bosses criticize, lovers flirt with others, and strangers take advantage. When such things happen, victims frequently experience antipathy toward those deemed responsible. They get mad, they get sad, and sometimes they get even. Other times, they forgive and even reconcile. To date, forgiveness researchers have tended to examine responses to wrongs that people have experienced directly, or what we might call firsthand forgiveness. The present studies examine the experience of forgiveness among people who have not been wronged directly but who merely identify with the victims of a transgression, which we refer to as secondhand forgiveness.

\section{The Psychology of Forgiveness}

Responses to transgressions contain cognitive (Fincham, 2000; Flanigan, 1992), affective (Brown \& Philips, 2005; Malcolm \& Greenberg, 2000), and motivational (Gordon, Baucom, \& Snyder, 2000; McCullough et al., 1998) features. Cognitive features include attributions of blame and ruminative thoughts about the event. Affective features include hostility toward the perpetrator, sadness about losing a relationship, or fear of future mistreatment. Motivational features include desires for revenge or avoidance, even to the point of severing relationships and seeking retribution. Although researchers have not reached consensus on a comprehensive definition or model of forgiveness, McCullough, Fincham, and Tsang (2003) argue that a shared feature of many definitions involves a positive shift in attitudes or motives toward a transgressor.

\footnotetext{
Authors' Note: Portions of this research were supported by a "Just-inTime" grant from the Society for the Psychological Study of Social Issues and a Social Sciences and Humanities Research Council of Canada grant. We gratefully acknowledge the insights of Glenn Reeder on Study 1 and the aid of Jennifer Bosson and Elizabeth Pinel in the Study 2 data collection. Please address correspondence to Ryan P. Brown, Department of Psychology, University of Oklahoma, 455 W. Lindsey, DHT 705, Norman, OK 73019; e-mail: rpbrown@ou.edu.
}

PSPB, Vol. 34 No. 10, October 2008 1406-1419

DOI: $10.1177 / 0146167208321538$

(C) 2008 by the Society for Personality and Social Psychology, Inc. 
Over the past decade, social psychologists have devoted increased attention to the topic of forgiveness, in part because of its positive role in interpersonal (see Fincham \& Beach, 2002; Fincham, Beach, \& Davila, 2004) and intergroup (Wohl \& Branscombe, 2005) relations. Furthermore, forgiveness appears to promote personal well-being (Brown, 2003; Witvliet, Ludwig, \& Vander Laan, 2001) and improve the physical health of victims (Toussaint, Williams, Musick, \& Everson, 2001). Thus, forgiveness not only benefits damaged relationships (also see Kachadourian, Fincham, \& Davila, 2005; Wohl, Kuiken, \& Noels, 2006), but it may also bring other benefits for forgivers.

Although forgiveness is often viewed as an internal process within victims, researchers have also noted the importance of interpersonal dynamics, particularly with respect to conciliatory efforts by transgressors (Darby \& Schlenker, 1982; Ohbuchi, Kameda, \& Agarie, 1989). For example, apologies can be powerful facilitators of forgiveness, but not when they are seen as insincere (Zechmeister, Garcia, Romero, \& Vas, 2004), a perception that is more likely when relationships were not close before the transgression (Brown, Phillips, \& Barnes, 2005).

\section{Forgiveness and Group Identification}

Although many studies have investigated forgiveness (Exline, Worthington, Hill, \& McCullough, 2003), little research has focused on those who feel offended because of harm done to another. A similar lack of attention to secondhand aggression characterizes the emotions literature, although recent studies of intergroup conflict have begun to address this shortcoming (Lickel, Miller, Stenstrom, Denson, \& Schmader, 2006; Yzerbyt, Dumont, Wigboldus, \& Gordijn, 2003). In the present studies, we apply concepts from intergroup conflict research, particularly social identity theory, to the dynamics of secondhand forgiveness.

Across a host of phenomena, social psychology has demonstrated ways that identifying with others can influence cognitions, emotions, and behavior. According to social identity theory (Tajfel \& Turner, 1986), for example, people interpret events based on their group memberships and the structural relations that exist between ingroups and outgroups. When people think of themselves as group members, their desire to protect their collective identity can lead them to appraise events in biased ways that benefit the ingroup (Baumeister \& Hastings, 1997; Leach, Iyer, \& Pedersen, 2007). Even minimal associations with others can promote ingroup loyalty and outgroup hostility (Hogg \& Abrams, 1988; Tajfel, Billig, Bundy, \& Flament, 1971). Indeed, people's emotions are frequently shaped by the extent to which they self-categorize as group members (Branscombe, Doosje, \& McGarty, 2002; Smith, 1993, 1999).

Even when people do not play a direct role in an event, they can have emotional reactions based on the meaning that the event has for valued social identities (Cialdini et al., 1976; Wohl, Branscombe, \& Klar, 2006). Likewise, they may react emotionally to harmful behavior directed at fellow ingroup members, even when they have not suffered direct harm themselves (Yzerbyt et al., 2003). As Smith (1999) argued, such group-based emotional responses rest on appraisals of an event's implications for social identity, whereas personal emotional responses center on implications for personal identity. Thus, harm directed toward an ingroup member might inflict secondhand harm on all who identify with that group, especially if the harm is clearly attributable to group membership (e.g., racial discrimination).

Direct harm might not be necessary for people to suffer psychological effects (e.g., Felsen, 1998; Wayment, 2004; Wohl \& Branscombe, in press). For example, children of Holocaust survivors exhibit increased vulnerability to posttraumatic stress disorder, including its neurochemical correlates (Yehuda et al., 2000). Furthermore, the transfer of such stress responses may extend beyond two generations (Klein-Parker, 1988). Following the September 11, 2001, attacks on the World Trade Center and the Pentagon, Wayment (2004) found that Americans who witnessed the attacks primarily via media exposure nonetheless experienced strong emotional reactions, including empathy for victimized ingroup members. She labeled people with such visceral reactions as vicarious victims.

Although Wayment (2004) assessed the impact of vicarious victimization and perceived similarity to the victim, her research did not investigate whether identification with the victim's group promoted empathy for ingroup members, or how identification might influence emotions in secondhand victims. In contrast, Yzerbyt and colleagues (2003) showed that anger was greater among participants who believed that transgression victims were ingroup members than among participants who believed victims were outgroup members. Anger also mediated the relationship between identification with a victim and certain "action tendencies" (e.g., desire to intervene). Thus, although some have argued that emotions are only experienced in situations that directly affect the self (Frijda, Kuipers, \& ter Shure, 1989), identification with a victim might effectively draw the self into a hurtful situation, creating secondhand forgiveness dynamics paralleling those of direct victims. We propose that considering such identification influences could help to delineate an important area of investigation. 
We argue that secondhand victimization might produce affective, cognitive, and behavioral reactions similar to those exhibited by firsthand victims. In particular, we suggest that identifying strongly with groups whose members have been wronged could promote empathy for ingroup victims, indignation toward perpetrators, and anxiety about the possibility of becoming a transgression target oneself. Whereas empathy and indignation might center on the harm done to firsthand victims, anxiety might be a more self-focused emotional reaction. Secondhand victims could, of course, experience both self-focused and other-focused emotions. Indeed, secondhand victims could easily alternate between emotions such as rage and fear, depending on where attention is focused at the moment. All such reactions, from attributions of blame, to empathy, to desires for revenge, could parallel the cognitive, affective, and motivational responses of firsthand victims.

Across three studies, we examined whether identification with a group whose members were harmed could evoke responses indicating a lack of forgiveness toward offenders. More specifically, we propose that identification with victim groups could lead to cognitive, affective, and motivational reactions similar to those demonstrated by those directly harmed, including empathy for victims, antipathy toward offenders, and desires to avoid wrongdoers and avenge the transgression. In Study 1, we focus on the motivational aspect of forgiveness, whereas in Study 2 we focus on both the cognitive and motivational aspects. In Study 3, we shift our focus to the affective aspect. Finally, in addition to examining the moderating role of group identification on the salutary effects of apologies (Study 1), we also provide preliminary tests of possible mediating mechanisms involved in secondhand forgiveness (Study 2 and 3).

\section{STUDY 1: GROUP IDENTIFICATION, FORGIVENESS, AND APOLOGIES}

In Study 1, we investigated whether individuals high or low in group identification would respond more favorably to an apology following a real-world transgression against ingroup members. If only individuals highly identified with the wronged group feel offended, then an apology might influence their secondhand forgiveness more than it would among the less identified, who might care less about both the offense and apology. Alternatively, if strongly identified individuals are more likely to feel resentment and hostility than are weakly identified individuals (e.g., Mackie, Devos, \& Smith, 2000; Yzerbyt et al., 2003), apologies might be less likely to placate them. If so, then psychological distance from the ingroup might actually enhance apology effectiveness for secondhand offenses, much as psychological closeness to the offender enhances apology effectiveness for firsthand offenses (Brown et al., 2005).

\section{The Offense}

On April 18, 2002, an American F-16 fighter jet dropped a 225-kilogram bomb near Kandahar, Afghanistan, killing four Canadian soldiers and injuring eight others. The accident sent Canadians into shock and mourning (Canadian Broadcasting Corporation [CBC], 2002). U.S. Air Force Major Harry Schmidt, the pilot involved in the "friendly fire" incident, was originally charged with four counts of involuntary manslaughter and eight counts of assault. Schmidt's wingman, Major William Umbach, was originally charged with four counts of aiding and abetting manslaughter and eight counts of aiding and abetting assault. A Canadian inquiry into the event revealed that Canada had notified American officers that soldiers would be doing live-fire exercises near Kandahar and that the U.S. Air Force was found to have acted inappropriately (CBC, 2003).

Pilot testing showed that although Canadians were very aware of the friendly fire deaths, little was known about the American government's official position and whether any apologies had been made. In Study 1, we experimentally manipulated the presence of an apology as part of the bogus report that participants read. We also wanted to examine the effects of an apology on intergroup relations. Apologies might be effective not only in altering internal states but also facilitating prosocial attitudes toward perpetrator groups and the maintenance of ongoing intergroup relations (Augoustinos \& LeCouteur, 2004). Thus, in addition to avoidance and revenge motives, we assessed whether the presence of an apology influenced Canadians' willingness to support American involvement in Afghanistan.

\section{METHOD}

\section{Participants}

Participants were 80 first-year psychology students (54 females, 26 males; all born in Canada) at Carleton University in Canada. Importantly, the university is located in the same city where the soldiers were stationed before they were killed in the attack in Kandahar. In the week following the incident, participants completed questionnaires for partial course credit. They were randomly assigned to either an apology or no apology condition.

\section{Procedure and Measures}

Participants completed four items assessing the extent to which they identified as Canadians: "I stand 
by Canadians," "I share Canadian values," "I feel close to other Canadians," and "I feel similar to other Canadians." Items were rated from 1 (not at all) to 7 (very much). The mean response to this identification measure was high $(M=5.14, S D=1.31, \alpha=.84)$. Participants were then told that they would read a newspaper article (ostensibly from the online edition of the CBC news) about the friendly fire deaths of four Canadian soldiers in Afghanistan. The bogus article depicted the events leading up to the deaths and the manner in which the soldiers were killed. In the apology condition, U.S. Defense Secretary Donald Rumsfeld was reported to have expressed his "deep regret and sadness over the tragic accident" and apologized to the families of the dead soldiers and to the Canadian Army for the actions of the U.S. Air Force. In the no apology condition, Mr. Rumsfeld was reported to have "assured his Canadian counterpart of Central Command's full cooperation in the investigation."

Forgiveness-related reactions were assessed with an adapted version of the Transgression-Related Interpersonal Motivations Inventory (McCullough et al., 1998). This 12-item scale contains two subscales focusing on revenge and avoidance motives. Participants responded to items such as "Canada should make the American Military pay" and "Canada should avoid involvement with the American Military" anchored at (1) strongly disagree and (5) strongly agree. In addition, 3 items anchored at (1) strongly disagree and (8) strongly agree assessed willingness to continue support of U.S. military endeavors in Afghanistan. These items were as follows: "Canada should continue to support U.S. efforts in Afghanistan," "Canada should stick by the U.S.'s side in its efforts in Afghanistan," and "Canada should withdraw support of U.S. led efforts in Afghanistan" (reversed).

When packets were completed, the experimenter probed for suspicion and debriefed participants. No participants expressed knowledge of the manipulation or the study's purpose.

\section{RESULTS}

\section{Preliminary Analyses}

No gender effects were found, so we collapsed across this variable in all analyses. To determine possible interactive effects of Canadian identification with the apology manipulation, a median split was conducted on the identification measure (median $=5.40)$. Participants scoring higher than 5.40 were categorized as high identifiers, and those scoring lower than 5.40 were categorized as low identifiers. Although breaking participants into two groups can lead to the loss of some of the variance accounted for by the original continuous variable (Cohen, 1983), the distribution of identification scores violated normality assumptions (Shipiro-Wilks $=.94$, $p<.0001)$ because of a strong negative skew $(-.73)$. Following logarithmic (Shipiro-Wilks $=.87, p<.001$ ) and inverse (Shipiro-Wilks $=.78, p<.001$ ) transformations, identification scores were still highly skewed (-1.30 and 1.86, respectively). Thus, a median split provided the most appropriate transformation for the identification variable.

\section{Manipulation Check}

As a check on the apology manipulation, participants were asked whether the United States offered an apology for the deaths of the Canadian soldiers. This item was anchored at (1) not at all and (8) extremely. As expected, participants in the apology condition perceived that the United States had apologized to a greater extent $(M=6.35, S D=1.61)$ than those in the no apology condition $(M=4.55, S D=1.78), F(1,78)=22.67$, $p<.001, d=1.06$.

\section{Avoidance and Revenge Motives}

The Transgression-Related Interpersonal Motivations Inventory subscales had high internal consistency estimates, with alphas of .87 and .80 for the Avoidance and Revenge subscales, respectively. Revenge also correlated significantly with Avoidance, $r=.59, p<.001$.

Avoidance. We conducted a 2 (apology: present vs. absent) $\times 2$ (identification: high vs. low) ANOVA on avoidance motives toward the American military. There were significant main effects for both apology and identification, $F(1,76)=29.64, p<.001$ and $F(1$, $76)=25.16, p<.001$, respectively. Participants in the no apology condition $(M=3.75, S D=.61)$ reported higher levels of avoidance motives than did participants in the apology condition $(M=3.00, S D=.92)$. Furthermore, high identifiers expressed greater avoidance motives $(M=3.68, S D=.75)$ than did low identifiers $(M=2.96, S D=.84)$. These main effects were qualified by a significant Apology $\times$ Identification interaction, $F(1,76)=4.35, p<.04$, as expected. Although the effect of the apology was significant at both levels of identification (see Table 1), the fact that the interaction was significant indicates that the attenuation of avoidance motives differed significantly between low identifiers and high identifiers. Specifically, the effect of an apology was significantly stronger among low identifiers, $F(1,76)=29.84, p<.001, d=1.84$, than among high identifiers, $F(1,76)=5.89, p<.02, d=0.71$. 
TABLE 1: Means for Avoidance and Revenge in Study 1 as a Function of Identification and Apology

\begin{tabular}{|c|c|c|c|c|c|c|c|c|}
\hline & \multicolumn{4}{|c|}{ High Identification } & \multicolumn{4}{|c|}{ Low Identification } \\
\hline & \multicolumn{2}{|c|}{ Avoidance } & \multicolumn{2}{|c|}{ Revenge } & \multicolumn{2}{|c|}{ Avoidance } & \multicolumn{2}{|c|}{ Revenge } \\
\hline & M & SD & M & SD & M & SD & M & SD \\
\hline No apology & 3.95 & 0.54 & 4.24 & 0.48 & 3.50 & 0.62 & 3.76 & 0.77 \\
\hline Apology & 3.43 & 0.85 & 3.63 & 0.61 & 2.35 & 0.60 & 2.40 & 0.53 \\
\hline Effect size of apology $(d)$ & 0.71 & & 1.09 & & 1.84 & & 1.99 & \\
\hline
\end{tabular}

NOTE: Means within each column are all significantly different at $p<.05$, using the Bonferroni correction.

Revenge. As with Avoidance, a 2 (apology) $\times 2$ (identification) ANOVA on Revenge revealed significant main effects for both apology and identification, $F(1$, $76)=51.06, p<.001$, and $F(1,76)=39.11, p<.001$, respectively. Participants in the no apology condition desired revenge $(M=4.02, S D=.66)$ more than participants in the apology condition $(M=3.14, S D=.84)$. Furthermore, high identifiers expressed stronger desires for revenge $(M=3.92, S D=.63)$ than did low identifiers $(M=3.12, S D=.95)$. These main effects were qualified by a significant Apology $\times$ Identification interaction, $F(1,76)=7.54, p<.009$, paralleling the results with avoidance motives. Although the apology attenuated revenge motives at both levels of identification (see Table 1), the significant interaction indicates that the apology reduced revenge motives significantly more among low identifiers, $F(1,76)=23.95, p<.001, d=$ 1.99 , than it did among high identifiers, $F(1,76)=$ $14.20, p<.001, d=1.09$.

\section{Continued Intergroup Support}

We next conducted a 2 (Apology) $\times 2$ (Identification) ANOVA on continued Canadian support of the American military. There was a significant effect of apology, $F(1,76)=50.38, p<.001$. Participants in the apology condition were more willing to continue Canadian support of American military efforts in Afghanistan $(M=4.72, S D=1.13)$ than were participants in the no apology condition $(M=3.00, S D=1.04)$. There was no main effect for identification with Canada, $p>.17$, and no Apology $\times$ Identification interaction, $p>.78$.

\section{DISCUSSION}

Study 1 showed that apologies had a significant effect on secondhand victims' willingness to forgive perpetrators, complementing a large literature on the benefits of apologies for firsthand victims. Importantly, some apology benefits were moderated by identification with the victimized group. Participants who were highly identified with the victimized group were less forgiving, as indicated by relatively strong revenge and avoidance motives. Although these motives were attenuated by an apology, the apology was particularly effective among those who were less identified with the victim group.

The results also suggest a policy-level implication of apologies following a secondhand offense. When apologies are not forthcoming, there may be reluctance on the part of ingroup members to continue supporting efforts of the transgressor group. That is, even if two groups have a history of mutual support, the absence of apology after a major offense (even an accidental one) might render offended parties less willing to continue support. This effect was not moderated by respondents' levels of identification with the harmed group, and in this way, the support variable differed from both avoidance and revenge. The reason for this difference is not readily apparent from these data; however, one possibility is that support was seen as a more impersonal, political response than the other forgiveness measures, rendering personal identification less crucial. Regardless of the exact explanation, the impact of apology on support was quite large, even though respondents were not the direct victims of the offense. Although the policy implications might be potentially interesting, it seems prudent to avoid further speculation until additional research examines this issue more closely.

\section{STUDY 2: GROUP IDENTIFICATION AND FORGIVENESS FOLLOWING A TERRORIST ATTACK}

Study 2 extended the results of Study 1 by examining reactions to another real-world offense-specifically, the attacks on the World Trade Center and the Pentagon on September 11, 2001-as a function of respondents' levels of identification with the United States. To evaluate whether identification was associated with aspects of secondhand forgiveness independent of direct, personal losses associated with the attack, we also measured the extent to which participants were related to or otherwise connected with firsthand victims of the attack. 
Study 2 also built upon recent work by Yzerbyt and colleagues (2003), who have shown that identification with a mistreated group can promote increased anger (but not typically sadness or fear; cf. Dumont, Yzerbyt, Wigboldus, \& Gordijn, 2003). Likewise, they demonstrated that the experience of vicarious anger mediated highly identified individuals' endorsement of what Yzerbyt et al. (2003) refer to as "offensive action tendencies," such as the desire to intervene. Study 2 complemented this research by examining emotional reactions of anger, sadness, and fear, as well as reactions even more directly related to forgiveness, including attributions of blame and desires for retribution, allowing us to test the mediating role of emotions in the cognitive and motivational aspects of secondhand forgiveness.

\section{METHOD}

\section{Participants}

During the 3 weeks following September 11, 2001, we administered a battery of questionnaires to 538 students (323 women and 215 men) at two large, public universities (The University of Oklahoma, $N=252$, and The Pennsylvania State University, $N=286$ ). Participants received partial course credit in introductory psychology for completing these questionnaires. Self-reported ethnicities included Caucasian (80.5\%), Asian (5.2\%), African American (4.3\%), Hispanic (1.9\%), Native American (1.7\%), Middle Eastern (1.5\%), and Other or Mixed ethnicity $(2.3 \%) ; 2.8 \%$ of the participants did not report their ethnicity.

\section{Measures and Procedure}

Three items assessed identification with America ("I consider myself to be very patriotic," "I have strong feelings of patriotism about the USA," and "I feel very proud to be a U.S. citizen," $\alpha=.88$ ), with a response scale anchored by definitely no (1) and definitely yes (7). In terms of secondhand forgiveness, participants rated the extent to which they (a) had already forgiven the attackers, (b) blamed those responsible for the attacks, and (c) wanted the perpetrators to be killed (referred to hereafter as "desire for retribution"). Each forgiveness facet was assessed with a single item rated from 1 (not at all) to 9 (completely).

Participants also completed items assessing the intensity and frequency with which they experienced various emotions during the weeks following the attacks on scales anchored by not at all or never (1) and very strongly or very often (9). Because the intensity and frequency items showed extremely similar patterns, we report only the intensity responses for the sake of simplicity. Among the emotional reactions assessed were anger, fear, and sadness, which Yzerbyt et al. (2003) examined in conjunction with transgressions against ingroup members.

Participants also reported the degree of personal impact they had experienced as a result of the attack. Specifically, they reported (a) whether any of their immediate or distant family members, close friends, acquaintances, or relatives or friends of someone they knew had been victims in the attack; and (b) if so, whether those persons had been killed, injured, or merely endangered. To examine strictly secondhand reactions, we excluded the responses of 7 respondents who indicated that a family member or close friend had died in the attack (these participants had thus suffered psychological losses of close relationships, so the nature of their victimization differed from that of the other participants). Data from 3 additional participants were also excluded because they failed to complete the ingroup identification measure. These exclusions left 528 participants in the final sample (318 women, 210 men).

\section{RESULTS}

An examination of gender differences revealed that women $(M=8.20, S D=1.36)$ reported more sadness than men $(M=7.43, S D=1.93), t(526)=5.35, p<$ .001 . Women $(M=6.56, S D=2.27)$ also reported more fear than men $(M=5.24, S D=2.58), t(526)=6.17, p<$ .001 . However, there were no gender differences on the forgiveness indices. Because gender was not a significant covariate in our analyses and did not change any associations of interest, we dropped this variable from the remaining analyses.

As shown in Table 2, group identification showed significant associations with every dimension of secondhand forgiveness, as well as all three emotional reactions (anger, sadness, and fear). The emotional reactions, in turn, were modestly associated with the three forgiveness variables (current forgiveness, blame, and desire for retribution). However, only anger was significantly associated with all three forgiveness indices (fear was associated with current forgiveness and blame, and sadness was linked only with blame).

Given the correlations among ingroup identification, emotions, and forgiveness (see Table 2), we wanted to examine the potential mediating role of emotions in the associations between identification and forgiveness. One approach would be to perform nine separate mediation analyses, one for each hypothesized emotion mediator with each forgiveness variable, with corresponding Sobel tests to assess the significance of the indirect (mediational) paths (Baron \& Kenny, 1986). However, this technique 
TABLE 2: Descriptive Statistics and Zero-Order Correlations Among Variables in Study 2

\begin{tabular}{|c|c|c|c|c|c|c|c|}
\hline & 1 & 2 & 3 & 4 & 5 & 6 & 7 \\
\hline 1. Identification & - & .32 & .14 & .14 & -.16 & .13 & .25 \\
\hline 2. Anger & & - & .28 & .36 & -.33 & .14 & .36 \\
\hline 3. Fear & & & - & .39 & -.09 & .11 & .06 \\
\hline 4. Sadness & & & & - & -.04 & .10 & .08 \\
\hline 5. Forgiveness & & & & & - & -.10 & -.42 \\
\hline 6. Blame & & & & & & - & .12 \\
\hline 7. Retribution & & & & & & & - \\
\hline$M$ & 5.55 & 6.85 & 6.03 & 7.89 & 2.41 & 7.56 & 6.12 \\
\hline$S D$ & 1.27 & 1.94 & 2.48 & 1.65 & 2.09 & 2.30 & 2.80 \\
\hline
\end{tabular}

NOTE: Correlation coefficients greater than $|r|=.08$ are significant at $p<.05$.

increases the risk of Type I error because so many significance tests must be performed. Furthermore, the standard Sobel test makes normality assumptions that are frequently violated in mediation tests, which can decrease statistical power and thereby increase Type II error (Preacher \& Hayes, 2004).

An alternative is to examine only three multiple-mediator models (one for each forgiveness variable) using a bootstrapping procedure described by Preacher and Hayes (in press). This procedure allows investigators to examine the significance of a set of potential mediators simultaneously, as well as the significance of each individual mediator, using confidence intervals to establish nonzero indirect paths. This multiple-mediator analysis also provides specific contrasts between each possible mediator, allowing conclusions about whether the indirect path from the focal predictor to the outcome variable is stronger through one mediator than through others.

Using this bootstrapping procedure (with 5,000 resamples), we tested three multiple mediator models, one for each forgiveness-related variable. The results of these models appear in Table 3, which presents the point estimation for each variable coefficient, as well as $95 \%$ confidence intervals (bias-corrected and accelerated) around each coefficient. If a confidence interval does not include 0 , then its corresponding coefficient is significantly different from 0 . In the present models, a nonzero coefficient indicates that a mediator variable significantly reduces the direct relationship between ingroup identification and a forgiveness-related variable.

As Table 3 shows, there was evidence for a mediational relationship when the set of hypothesized mediators was considered as a whole in connection with current forgiveness levels. Specifically, both anger and sadness mediated the association between identification and current forgiveness. Fear did not emerge as a significant mediator in this model. The indirect path through anger was also significantly stronger than the indirect paths through sadness and fear, as indicated by the contrasts in Table 3. Because the direct path from identification to current forgiveness was no longer significant with the mediators in the model $(B=-0.104, t=$ $-1.45, p>.14)$, we can conclude that full mediation was demonstrated by this model, primarily through anger and (to a lesser extent) sadness.

For blame, the set of mediators together was again significant. However, none of the emotions was significant when controlling for the presence of the other emotions, which suggests that collinearity among the emotion variables might have obscured their mediational roles in this analysis. When we tested a mediation model with anger alone using this bootstrapping procedure (with 5,000 resamples), the indirect path through anger was indeed significant (point estimate $=0.065$, $95 \%$ confidence interval from 0.012 to 0.0138 ). Likewise, a similar model including only fear showed that the indirect path through this emotion was significant (point estimate $=0.0245,95 \%$ confidence interval from 0.0024 to 0.0654$)$. In contrast, the indirect path through sadness was not quite significant (point estimate $=0.0217,95 \%$ confidence interval from 0.0000 to 0.0669 ), as the confidence interval contained 0 . Because the direct path from identification to blame was no longer significant with the full set of mediators included $(B=0.154, t=1.86, p>.05)$, we can conclude that full mediation was demonstrated by this model, primarily through anger and fear.

Finally, for retribution, the multiple-mediator model revealed that the set of mediators together was again significant. However, the indirect path from identification to retribution was significant only through anger, which was also a significantly better mediator than both sadness and fear, as indicated by the nonzero contrasts shown in Table 3 for retribution. Because the direct path from identification to retribution remained significant with the mediators in the model $(b=0.332, t=$ $3.53, p<.001)$, we can conclude that this model demonstrated partial mediation. 
TABLE 3: Mediation of the Association Between Ingroup Identification and Forgiveness Variables

\begin{tabular}{|c|c|c|c|}
\hline & \multirow[b]{2}{*}{ Point Estimate } & \multicolumn{2}{|c|}{$95 \%$ Confidence Interval } \\
\hline & & Lower & Upper \\
\hline \multicolumn{4}{|l|}{ Forgiveness } \\
\hline Total mediator set & -.164 & -.254 & -.095 \\
\hline Anger & -.179 & -.275 & -.108 \\
\hline Sadness & .023 & .004 & .062 \\
\hline Fear & -.008 & -.037 & .013 \\
\hline Anger versus sadness & -.202 & -.312 & -.119 \\
\hline Anger versus fear & -.172 & -.270 & -.098 \\
\hline \multicolumn{4}{|l|}{ Blame } \\
\hline Total mediator set & .074 & .017 & .152 \\
\hline Anger & .049 & -.008 & .121 \\
\hline Sadness & .009 & -.014 & .052 \\
\hline Fear & .016 & -.006 & .056 \\
\hline \multicolumn{4}{|l|}{ Retribution } \\
\hline Total mediator set & .215 & .128 & .318 \\
\hline Anger & .241 & .155 & .346 \\
\hline Sadness & -.017 & -.053 & .007 \\
\hline Fear & -.009 & -.043 & .021 \\
\hline Anger versus sadness & .257 & .165 & .378 \\
\hline Anger versus fear & .249 & .157 & .360 \\
\hline
\end{tabular}

NOTE: Confidence intervals are bias corrected and accelerated; intervals not including 0 indicate a significant mediator (or a significant difference between mediators).

\section{DISCUSSION}

Study 2 showed that identification with a group that has been attacked was associated with less forgiveness, more blame, and more desire for retribution, even among individuals who had not experienced a direct, personal loss. Furthermore, Study 2 showed that group identification was positively associated with anger, fear, and sadness. Consistent with prior research by Yzerbyt and colleagues (2003), anger was the strongest and most consistent mediator of the associations between group identification and forgiveness. We should note, however, that very high levels of sadness and blame were observed in this study (see Table 2), which is not surprising, given the magnitude and nature of the transgression. The high levels of sadness and blame suggest that range restriction might have attenuated the strength of mediation by sadness and the overall results for blame. Future studies on transgressions that involve more moderate levels of sadness and blame might reveal stronger results for these variables.

Consistent with Study 1, Study 2 suggests that people might not always forgive a transgression even when they are not the direct targets of harm, and this lack of forgiveness is particularly strong among individuals who are highly identified with a victimized group. Note, however, that other potentially important variables (i.e., empathy for firsthand victims, fear of being a target oneself) were not included in Study 2. Furthermore, Study 2 was based entirely on correlational data, making it impossible to establish causation. For example, emotional reactions to the attacks could have enhanced ingroup identification (e.g., Jetten, Branscombe, Schmitt, \& Spears, 2001), which in turn might have decreased forgiveness, rather than the sequence we have proposed. Because examining all of these variables in an experimental context is the only way to clarify the causal sequence, we conducted Study 3.

\section{STUDY 3: ASSIMILATION, DIFFERENTIATION, AND SECONDHAND FORGIVENESS}

According to Pickett, Silver, and Brewer (2002), belonging to a social group becomes more important to people when assimilation needs are aroused and less important when differentiation needs are aroused. That is, group identification motives are enhanced when people feel they are too different from those around them. Conversely, when people feel they are too similar to those around them, their desires shift toward expression of personal uniqueness rather than group identification. In Study 3, we manipulated participants' desires for group identification using instructions designed to arouse either assimilation or differentiation needs. Afterward, participants read a bogus newspaper article that depicted ingroup members being assaulted by members of an outgroup. Specifically, Canadian participants read that two fellow Canadians were attacked by German youths. Forgiveness-related feelings toward the perpetrators were then assessed. 
We also measured several intermediate variables presumed to underlie secondhand forgiveness dynamics. First, we assessed empathy as a potential mediator of the identification-forgiveness association. Empathy involves a tendency to be sensitive to, and vicariously experience, the feelings, thoughts, and emotions of others (Batson \& Shaw, 1991) - a process that tends to increase concern about their welfare (Batson, 1998). We hypothesized that identification would enhance empathy for victimized ingroup members. When empathy is felt toward a victim, there should be a decreased willingness to forgive the transgressor (see Schimel, Wohl, \& Williams, 2006).

We also assessed whether the manipulation influenced mood (hostility, anxiety) and concern about suffering a similar attack oneself. These measures were included as additional mechanisms by which identification could influence secondhand forgiveness (beyond the role of empathy). If participants become concerned about being similarly attacked, their ability or desire to forgive could be reduced. Likewise, feelings of hostility and anxiety following a transgression could undermine forgiveness, although only the former was supported by the correlational results of Study 2. In sum, Study 3 manipulated group assimilation and differentiation needs, rather than simply measuring group identification levels, and examined self-focused and other-focused concerns alongside several emotional indices as possible mediators of the effects of identification needs on forgiveness.

\section{METHOD}

\section{Participants}

Participants were 113 (34 male and 79 female) introductory psychology students at Carleton University in Canada, all of whom received extra credit for participation. They ranged in age from 17 to 36 years $(M=20.43$, $S D=3.54)$, and all were Canadian born. Ethnicities included European Canadian $(n=84)$, Asian Canadian $(n=9)$, African Canadian $(n=5)$, Aboriginal $(n=3)$, Hispanic Canadian $(n=3)$, Arab Canadian $(n=1)$, and Other $(n=8)$.

\section{Design and Procedure}

Participants completed the study online. Prior to accessing the Web site, participants read that the study concerned psychological elements of communication, including the impact of narrative elements in news stories and their relation to story effectiveness. Participants were told that they would be asked to read a news brief, ostensibly from a local newspaper. After granting consent, participants were randomly assigned to one of three Web sites that corresponded to three conditions. To elicit assimilation or differentiation needs, we used Sahdra and Ross's (2007) modification of Pickett et al.'s (2002) instructions. In the differentiation condition $(n=$ 37), participants were told, "News events focus on events that occur to others. In anticipation of reading the upcoming article, we ask you to think about times you felt too similar to other people, so similar that you felt uncomfortable." In the assimilation condition, participants $(n=39)$ were instead told " ... to think about times you felt too different from people, so different that you felt uncomfortable." In the control condition, participants $(n=37)$ were told to "think about times you felt that you were similar to some people around you but different from other people."

Next, all participants were routed to a Web page that had the appearance of the world news section of a local newspaper. They then read a story of two Canadian university students (Daniel Radford and Julie Barton) who were backpacking together in Hamburg, Germany. The story reported that during a muggy evening in downtown Hamburg, the two were assaulted by a small group of hooded individuals who also directed derogatory language at them. Both Canadian students sustained injuries from the attack. The story concluded with Canadian Police decrying the incident and asking that Hamburg Police work hard to find those responsible.

After participants read the bogus news article, they were presented with a survey about the events. Initial survey items were included to maintain the cover story. For example, participants rated how well written the story was, whether the author communicated the events vividly, if the story was engaging, and whether the article transported them into the narrative. The survey continued with items assessing the dependent measures (secondhand forgiveness items) and the potential mediators (empathy for the victim, concern about being personally attacked, anxiety, and hostility). Presentation of these items was randomized. Upon completing these measures, participants were automatically directed to a Web site for a written debriefing.

\section{Measured Variables}

Secondhand forgiveness. Seven items assessed feelings of forgiveness toward the attackers $(\alpha=.81)$, based loosely upon the State Forgiveness Scale described by Brown and Phillips (2005). These items were as follows: "I forgive those responsible for this assault," "I feel very cold toward those responsible for the attack (reversed)," "I would like to see those responsible punished harshly [reversed]," "I do not feel any ill-will at all toward those responsible for the attack," "I would never be willing to associate with those responsible for 
the attack [reversed]," "I do not feel any resentment whatsoever toward those responsible for the attack," and "I feel a great deal of animosity toward those responsible for the attack [reversed]," with (1) strongly disagree and (7) strongly agree as endpoints.

Empathy for the victims. The extent to which participants empathized with the Canadian victims was assessed with four items $(\alpha=.74)$ : "I feel sorry for the victims of this attack," "I feel empathy for the victims of this attack," "I don't care much one way or the other about the victims of this attack [reversed]," and "I really feel the pain of the victims of this attack," anchored at 1 (strongly disagree) and 7 (strongly agree).

Concern about being attacked. Three items assessed the extent to which participants were concerned that they would similarly be attacked $(\alpha=.71)$ : "I feel worried that I, too, might be attacked," "I feel uncertain about my own safety," and "I feel perfectly safe [reversed]," anchored at 1 (strongly disagree) and 7 (strongly agree).

Hostile and anxious mood. To assess possible mood variations as a function of the manipulation, participants indicated the extent to which they felt anxious and hostile while reading the news story. Anxiety was a composite of the extent to which participants felt anxious, afraid, worried, and fearful $(\alpha=.83)$. Hostility was a composite of the extent to which participants felt hostile, angry, furious, displeased, and irritated $(\alpha=$ .86). Responses were anchored at 1 (not at all) and 7 (very much). These emotion indices were correlated very highly, $r=.87, p<.001$, but we kept them separate in analyses because of conceptual distinctiveness.

\section{Result}

Preliminary analysis. We first conducted a two-way between-groups ANOVA (Condition $\times$ Gender) on all dependent variables. Only one gender effect was found: Females reported more worry about being attacked $(M=3.92, S D=1.85)$ than did males $(M=3.02, S D=$ $1.54), F(1,107)=10.26, p=.002$. Because there were no other main effects of gender, $p s>.14$, nor any gender interactions, $p s>.18$, we collapsed across gender for all subsequent analyses.

As a manipulation check, we assessed the extent to which participants identified as Canadian (modified from Wohl \& Branscombe, 2005). These items were as follows: "I am proud to be a Canadian," "I identify with Canada," "Being Canadian is important to me," and "I feel a connection with other Canadians," with (1) strongly disagree and (7) strongly agree as endpoints $(\alpha=.90)$. As indicated by a one-way ANOVA, our manipulation of the need to identify with a group was successful, $F(2,110)=6.51, p=.002$. Participants in the assimilation condition $(M=6.11, S D=0.70)$ reported greater identification with Canada than participants in the differentiation $(M=5.52, S D=0.86)$ and control conditions $(M=5.54, S D=1.26), p s<.03$. It is noteworthy, however, that identification was rather high in all conditions, and self-reported identification did not decrease in the differentiation condition. As well, we assessed whether participants correctly recalled the victims as being Canadian, which all participants did successfully.

\section{Dependent Measures}

Secondhand forgiveness. The seven secondhand forgiveness items were averaged to create an overall secondhand forgiveness score. As predicted, a one-way ANOVA showed a significant condition effect, $F(2$, $110)=3.37, p=.04$. Participants in the assimilation condition $(M=3.18, S D=0.99)$ reported less forgiveness than participants in the differentiation condition $(M=3.75, S D=0.78), p=.01$. Neither the assimilation nor differentiation condition was significantly different from the control condition $(M=3.35, S D=1.14)$, ps $>.08$.

Empathy for the victims. A one-way ANOVA revealed a significant effect of condition on the extent to which participants empathized with the victims, $F(2,110)=$ $4.08, p=.01$. Participants in the assimilation condition reported greater empathy $(M=4.94, S D=1.19)$ than did participants in the differentiation condition $(M=$ $4.19, S D=1.30), p<.01$. Control participants $(M=$ 4.91, $S D=1.03$ ) did not differ significantly from those in the assimilation condition, $p>.90$, but did differ significantly from those in the differentiation condition, $p=.01$.

Worry about being attacked. An ANOVA showed no differences among the assimilation $(M=3.38, S D=$ 1.49), differentiation $(M=3.87, S D=1.41)$, or control conditions $(M=3.71, S D=1.36)$ on worry about being attacked, $F(2,110)=1.19, p=.31$.

Mood. An ANOVA revealed that neither anxiety (assimilation, $M=3.79, S D=1.54$, vs. differentiation, $M=3.24, S D=1.76$, vs. control $M=3.07, S D=1.57$ ) nor hostility (assimilation, $M=3.81, S D=1.55$, vs. differentiation, $M=3.28, S D=1.57$, vs. control $M=3.28$, $S D=1.42)$ differed by condition, $F(2,110)=2.08$, $p=.13$ and $F(2,110)=1.54, p=.22$, respectively. 


\section{Mediation Analyses}

Our focus in Study 3 was on how participants in the assimilation condition differed from those in the differentiation condition. Thus, a mediational analysis was conducted excluding participants in the control condition, who consistently fell between the other two groups on our outcome measures. To determine if the effect of our manipulation on secondhand forgiveness could be explained by empathy for the victims (the only hypothesized mediator that was significantly influenced by our manipulation), we used Baron and Kenny's (1986) procedure for testing mediation. Because the ANOVAs showed that the manipulation reliably affected both secondhand forgiveness and empathy for the victims, we proceeded to test the full model. Thus, the manipulation variable (dummy coded as 0 in the differentiation condition and 1 in the assimilation condition) and empathy were included in a regression equation with secondhand forgiveness as the dependent variable, $R^{2}=.37, F(2,73)=21.70, p<$ .001 . The coefficient associated with empathy was significant, $\beta=-.55, t(74)=-5.69, p<.001$, but the manipulation variable no longer significantly predicted state forgiveness, $\beta=-.15, t(74)=-1.53, p>.13$.

We then used the bootstrapping technique (with 1,000 iterations) recommended by Preacher and Hayes (2004) for small samples to determine whether the indirect effect of the manipulation on secondhand forgiveness was due to increased empathy for the victims. The indirect effect was estimated to lie between -1.16 and -.06 , with $95 \%$ confidence. Because 0 is not in the $95 \%$ confidence interval, the indirect effect was indeed significantly different from 0 at $p<.05$ (two tailed). Thus, we concluded that empathy did indeed mediate the effects of the manipulation on secondhand forgiveness.

\section{DISCUSSION}

Complementing results from our first two studies, Study 3 revealed that a manipulation designed to heighten or diminish identification motives influenced state forgiveness for a secondhand transgression. Furthermore, this effect was mediated by empathy for the firsthand victims of the transgression but not by expectations of personal victimization. Although the experimental manipulation of identification motives went beyond the correlational assessment of group identification in Studies 1 and 2, this study has its own limitations. For example, the transgression was less serious than those in either of the first two studies, involving a mere physical assault that did not result in anyone's death. Likewise, participants' experience with this transgression was limited completely to the experimental context in which they merely read about the assault, whereas in Studies 1 and 2, participants had multiple opportunities to hear about, witness, and discuss the offense with other members of their ingroup. This difference could help explain why hostility was not significantly influenced by our Study 3 manipulation, although anger was the most consistent mediator of the identification-forgiveness associations in Study 2.

In addition, our manipulation check revealed that the assimilation condition increased ingroup identification relative to a control condition; however, ingroup identification was not diminished in the differentiation condition. This difference stands in contrast to the pattern of means regarding forgiveness and empathy, on which the largest differences occurred with the differentiation condition. It is possible that our manipulation was not strong enough to reduce self-reports of identification with Canada among a sample that displayed rather high identification levels. Thus, we might have successfully dampened the affiliative motives associated with a group identity without reducing the desire to maintain the appearance of ingroup loyalty. Indeed, the need to belong is a powerful motivator of social behavior (Baumeister \& Leary, 1995), and disclaiming loyalty to an established ingroup can be a risky course of action (see Levine \& Moreland, 2002), even when one is not feeling especially "group-ish." Thus, despite the overall success of our manipulation with regard to forgiveness and empathy, more research is needed to clarify the kinds of self-reported motives, attitudes, and behaviors produced by manipulating assimilation and differentiation needs.

\section{GENERAL DISCUSSION}

The major purpose of this research was to provide evidence for the relevance of forgiveness among people who have not been personally harmed but who nevertheless identify with the targets of a perceived wrongdoing. Specifically, based on the reasoning that victimization can be experienced vicariously (see Lickel et al., 2006; Wayment, 2004; Yehuda et al., 2000; Yzerbyt et al., 2003), we assessed the experience of secondhand forgiveness in a variety of transgression contexts. Across three studies, forgiveness-related indices were shown to vary based on the extent to which people identified with ingroup members who had suffered direct harm. Thus, when a fellow ingroup member is harmed, people who identify strongly with the ingroup might feel vicariously harmed as well, making forgiveness difficult.

As shown in Study 1, apologies can reduce people's reluctance to forgive a transgressor who has wronged a member of their ingroup. Importantly, the association between willingness to forgive and the presence of an 
apology interacted with group identification level, such that the forgiveness-related benefits of an apology were enhanced as identification with the victimized group diminished. The results of Study 1 complement those by Brown et al. (2005), who showed that apologies for firsthand offenses were more effective when they came from offenders who were relationally close as opposed to distant. Together, these studies suggest that apologies might more effectively elicit forgiveness if they are given by a transgressor who is close to a firsthand victim, or if they are given to someone who is not close to the victimized group. In other words, psychological distance from an offender reduces the effectiveness of apologies for firsthand offenses, whereas psychological distance from an offended group enhances the effectiveness of apologies for secondhand offenses.

In Study 2, participants reflected on another serious, real-world event in which ingroup members were victims of terrorism. Consistent with predictions, the extent to which participants identified with America was negatively associated with forgiveness toward the perpetrators of the 9/11 attacks. Indeed, the more strongly participants felt a connection to America, the less they forgave the perpetrators, the more they blamed them, and the greater their desire was for deadly retribution. These forgiveness dynamics were mediated, for the most part, by the anger experienced by highly identified respondents, consistent with prior research by Yzerbyt and colleagues (2003). Fear and sadness were weaker and less consistent mediators, although each appeared to play a small role across the indices of secondhand forgiveness that we assessed. Study 2 thus helped to identify several emotional mechanisms through which identification might render secondhand forgiveness difficult.

Finally, in Study 3 we examined the effects of manipulating group identification motives on secondhand forgiveness. This study showed that people whose identification needs were enhanced experienced less forgiveness than those whose identification needs were diminished, and that this effect was mediated by empathy for ingroup victims. In contrast, secondhand victims' expectation that they might share the misfortune of ingroup members did not drive this reduction in forgiveness. Thus, reduced identification motives do not eliminate a group identity per se. People in the differentiation condition remained part of the ingroup to which the firsthand victims belonged, and as fellow group members, they remained potential targets of outgroup hostility. However, the reduction in group identification needs seemed to reduce empathic feelings toward ingroup members, thus allowing people to feel more forgiving toward outgroup transgressors.

We should note, however, that even though expectations of victimization did not mediate the forgiveness effects observed in Study 3, other situations might produce such expectancy-driven reductions in secondhand forgiveness. Future studies might examine this possibility by varying the prominence of the intergroup context and the appearance of group identity as a motive for transgressions. As well, such studies might also manipulate the severity of the transgression itself. Perhaps when life-ordeath issues are at stake, anxious expectations of personal victimization will play a more important role in secondhand forgiveness dynamics than they did in Study 3.

Thus, in three studies in which someone other than the self was directly harmed, stronger identification with the group to which firsthand victims belonged was associated with lower forgiveness levels. Broadly speaking, the phenomenon of secondhand forgiveness might have relevance for the study of ethno-political conflicts. In a world replete with violent feuds between and within countries and across ethnic, racial, and political groups, it is important to understand the complex roles played by group identification among those not directly harmed by outgroup members. People who vicariously experience secondhand offenses may feel victimized by perpetrators and might engage in vicarious retribution in response (Lickel et al., 2006), which may serve to prolong and escalate intergroup hostilities. Of course, the present data focus on the intrapersonal dynamics of secondhand victimization, and large-scale ethno-political conflicts no doubt involve more complicated interpersonal dynamics than those captured in these studies. Future research examining such grouplevel dynamics, including the roles of group cohesiveness and leadership, could advance our understanding of secondhand forgiveness processes beyond the present studies. Likewise, studies that investigate secondhand forgiveness in dyadic relationships could also prove valuable, as group-level identification could easily translate into person-level identification (e.g., Aron, Aron, \& Smollan, 1992), leading people to take up offenses on behalf of loved ones who have been directly victimized.

The studies presented here demonstrate that outgroup transgressions that affect fellow ingroup members, without directly affecting the self, can elicit strong emotional reactions. When an ingroup member is harmed, those who identify with the victim through a shared group identity can also experience that harm, albeit indirectly. Such vicarious harm may result in anger and concomitant behaviors directed at transgressors, and possibly even at those who are associated with them (Lickel et al., 2006). Our hope is that the present studies can contribute to the literatures on intergroup relations, social emotions, and interpersonal forgiveness by showing how these diverse domains may find common ground in the dynamics of secondhand forgiveness. 


\section{REFERENCES}

Aron, A., Aron, E. N., \& Smollan, D. (1992). Inclusion of other in the self scale and the structure of interpersonal closeness. Journal of Personality and Social Psychology, 63, 596-612.

Augoustinos, M., \& LeCouteur, A. (2004). On whether to apologize to Indigenous Australians: The denial of white guilt. In N. R. Branscombe \& B. Doosje (Eds.), Collective guilt: International perspectives (pp. 552-609). New York: Cambridge University Press.

Baron, R. M., \& Kenny, D. A. (1986). The moderator-mediator variable distinction in social psychological research: Conceptual, strategic, and statistical considerations. Journal of Personality and Social Psychology, 51, 1173-1182.

Batson, C. D. (1998). Altruism and prosocial behavior. In D. T. Gilbert, S. Fisk, \& L. Gardner (Eds.), The handbook of social psychology, (Vol. 2, pp. 282-316). Boston: McGraw Hill.

Batson, C. D., \& Shaw, L. L. (1991). Encouraging words concerning the evidence for altruism. Psychological Inquiry, 2, 159-168.

Baumeister, R. F., \& Hastings, S. (1997). Distortions of collective memory: How groups flatter and deceive themselves. In J. W. Pennebaker, D. Paez, \& B. Rimé (Eds.), Collective memory of political events: Social psychological perspectives (pp. 277- 293). Mahwah, NJ: Lawrence Erlbaum.

Baumeister, R. F., \& Leary, M. R. (1995). The need to belong: Desire for interpersonal attachments as a fundamental human motivation. Psychological Bulletin, 117, 497-529.

Branscombe, N. R., Doosje, B. J., \& McGarty, C. (2002). Collective guilt: Antecedents, correlates and consequences. In D. M. Mackie $\&$ E. R. Smith (Eds.) From prejudice to intergroup relations: Differentiated reactions to social groups (pp. 49-66). New York: Psychology Press.

Brown, R. P. (2003). Measuring individual differences in the tendency to forgive: Construct validity and links with depression. Personality and Social Psychology Bulletin, 29, 759-771.

Brown, R. P., \& Phillips, A. (2005). Letting bygones be bygones: Further evidence for the validity of the tendency to forgive scale. Personality and Individual Differences, 38, 627-638.

Brown, R. P., Phillips, A., \& Barnes, C. (2005, January). When apologies fail: Mea culpa and the intimacy effect. Symposium presentation at the 6th annual meeting of the Society for Personality and Social Psychology, New Orleans, LA.

Canadian Broadcasting Corporation. (2002, April 19). Canadians shocked, saddened, outraged by deaths. Retrieved November 24, 2005, from http://www.cbc.ca/news

Canadian Broadcasting Corporation. (2003, October 22). The 'friendly fire' report. Retrieved November 24, 2005, from http://www.cbc.ca/news

Cialdini, R. B., Borden, R. J., Thorne R. J., Walker, M. R., Freeman, S., \& Sloan, L. R. (1976). Basking in reflected glory: Three (football) field studies. Journal of Personality and Social Psychology, 34, 366-375.

Cohen, J. (1983). The cost of dichotomization. Applied Psychological Measurement, 7, 249-253.

Darby, B. W., \& Schlenker, B. R. (1982). Children's reactions to apologies. Journal of Personality and Social Psychology, 43, 742-753.

Dumont, M., Yzerbyt, V., Wigboldus, D., \& Gordijn, E. H. (2003). Social categorization and fear reactions to the September 11th terrorist attacks. Personality and Social Psychology Bulletin, 29, 1509-1520.

Exline, J. J., Worthington, E. L., Hill, P., \& McCullough, M. E. (2003). Forgiveness and justice: A research agenda for social and personality psychology. Personality and Social Psychology Review, 7, 337-348.

Felsen, I. (1998). Transgenerational transmission of effects of the Holocaust: The North American research perspective. In Y. Danieli (Ed.), International handbook of multigenerational legacies of trauma (pp. 43-68). New York: Plenum.

Fincham, F. D. (2000). The kiss of the porcupines: From attributing responsibility to forgiving. Personal Relationships, 7, 1-23.
Fincham, F. D., \& Beach, S. R. (2002). Forgiveness in marriage: Implications for psychological aggression and constructive communication. Personal Relationships, 9, 239-251.

Fincham, F. D., Beach, S. R., \& Davila, J. (2004). Forgiveness and conflict resolution in marriage. Journal of Family Psychology, 18, 72-81.

Flanigan, B. (1992). Forgiving the unforgivable: Overcoming the bitter legacy of intimate wounds. New York: Macmillan.

Frijda, N. H., P. Kuipers, P., \& ter Shure, E. (1989). Relations among emotion, appraisal and emotional action readiness. Journal of Personality and Social Psychology, 57, 212-228.

Gordon, K. C., Baucom, D. H., \& Snyder, D. K. (2000). The use of forgiveness in marital therapy. In M. E. McCullough, K. I. Pargament, \& C. E. Thoresen (Eds.), Forgiveness: Theory, research, and practice (pp. 203-227). London: Guilford.

Hogg, M. A., \& Abrams, D. (1988). Social identifications: A social psychology of intergroup relations and group processes. London: Routledge.

Jetten, J., Branscombe, N. R., Schmitt, M. T., \& Spears, R. (2001). Rebels with a cause: Group identification as a response to perceived discrimination from the mainstream. Personality and Social Psychology Bulletin, 27, 1204-1213.

Kachadourian, L. K., Fincham, F., \& Davila, J. (2005). Attitudinal ambivalence, rumination, and forgiveness of partner transgressions in marriage. Personality and Social Psychology Bulletin, 31, 334-342.

Klein-Parker, F. (1988). Dominant attitudes of adult children of Holocaust survivors toward their parents. In J. P. Wilson, Z. Harel, and B. Kahana, (Eds.) Human adaptation to extreme stress: From the Holocaust to Vietnam (pp. 193-218). New York: Plenum.

Leach, C. W., Iyer, A., \& Pedersen, A. (2007). Angry opposition to government redress: When the structurally advantaged perceive themselves as relatively deprived. British Journal of Psychology, 46, 191-204.

Levine, J. M., \& Moreland, R. L. (2002). Group reactions to loyalty and disloyalty. In E. Lawler \& S. Thye (Eds.), Group cohesion, trust, and solidarity: Advances in group processes (Vol. 19, pp. 203-228). Amsterdam: Elsevier Science.

Lickel, B., Miller, N., Stenstrom, D. M., Denson, T. F., \& Schmader, T. (2006). Vicarious retribution: The role of collective blame in intergroup aggression. Personality and Social Psychology Review, 10, 372-390.

Mackie, D. M., Devos, T., \& Smith, E. R. (2000). Intergroup emotions: Explaining offensive action tendencies in an intergroup context. Journal of Personality and Social Psychology, 79, 602-616.

Malcolm, W. M., \& Greenberg, L. S. (2000). Forgiveness as a process of change in individual psychotherapy. In M. E. McCullough, K. I. Pargament, \& C. E. Thoresen (Eds.), Forgiveness: Theory, research, and practice (pp. 179-202). New York: Guilford.

McCullough, M. E., Fincham, F. D., \& Tsang, J. A. (2003). Forgiveness, forbearance, and time: The temporal unfolding of transgression-related interpersonal motivations. Journal of Personality and Social Psychology, 84, 540-557.

McCullough, M. E., Rachal, K. C., Sandage, S. J., Worthington, E. L., Brown, S. W., \& Hight, T. (1998). Interpersonal forgiving in close relationships: II. Theoretical elaboration and measurement. Journal of Personality and Social Psychology, 75, 1586-1603.

Ohbuchi, K., Kameda, M., \& Agarie, J. (1989). Apology and aggression control: Its role mediating appraisal of and response to harm. Journal of Personality and Social Psychology, 56, 219-227.

Pickett, C. L., Silver, M. D., \& Brewer, M. B. (2002). The impact of assimilation and differentiation needs on perceived ingroup importance and judgments of ingroup size. Personality and Social Psychology Bulletin, 28, 546-558.

Preacher, K. J., \& Hayes, A. F. (2004). SPSS and SAS procedures for estimating indirect effects in simple mediation models. Behavior Research Methods, Instruments, and Computers, 36, 717-731.

Preacher, K. J., \& Hayes, A. F. (in press). Asymptotic and resampling strategies for assessing and comparing indirect effects in multiple mediator models. Behavior Research Methods. 
Sahdra, B., \& Ross, M. (2007). Group identification and historical memory. Personality and Social Psychology Bulletin, 33, 384-395.

Schimel, J., Wohl, M. J. A., \& Williams, T. (2006). Terror management and trait empathy: Evidence that mortality salience promotes reactions of forgiveness among people with high (vs. low) trait empathy. Motivation and Emotion, 30, 217-227.

Smith. E. R. (1993). Social identity and social emotions: Towards new conceptualizations of prejudice. In D. Mackie \& D. Hamilton (Eds.), Affect, cognition, and stereotyping: Interactive processes in group perception (pp. 297-315). San Diego, CA: Academic Press.

Smith, E. R. (1999). Affective and cognitive implications of a group becoming part of the self: New models of prejudice and of the selfconcept. In D. Abrams \& M. Hogg (Eds.), Social identity and social cognition (pp. 183-196). Malden, MA: Blackwell.

Tajfel, H., Billig, M. G., Bundy, R. P., \& Flament, C. (1971). Social categorization and intergroup behavior. European Journal of Social Psychology, 1, 149-178.

Tajfel, H., \& Turner, J. C. (1986). The social identity theory of intergroup behavior. In W. G. Austin \& S. Worchel (Eds.), The social psychology of intergroup relations (pp. 7-24). Monterey, CA: Brooks/Cole.

Toussaint, L. L., Williams, D. R., Musick, M. A., \& Everson, S. A. (2001). Forgiveness and health: Age differences in a US probability sample. Journal of adult development, 8, 249-257.

Wayment, H. A. (2004). It could have been me: Vicarious victims and disaster-focused distress. Personality and Social Psychology Bulletin, 30, 515-528.

Witvliet, C. V. O., Ludwig, T. E., \& Vander Laan, K. L. (2001). Granting forgiveness or harboring grudges: Implications for emotion, physiology, and health. Psychological Science, 12, 117-123.
Wohl, M. J. A., \& Branscombe, N. R. (2005). Forgiveness and collective guilt assignment to historical perpetrator groups depends on level of social category inclusiveness. Journal of Personality and Social Psychology, 88, 288-303.

Wohl, M. J. A., \& Branscombe, N. R. (in press). Remembering historical victimization: Collective guilt for current ingroup transgressions. Journal of Personality and Social Psychology.

Wohl, M. J. A., Branscombe, N. R., \& Klar, Y. (2006). Collective guilt: An emotional response to perceived ingroup misdeeds. European Review of Social Psychology, 17, 1-37.

Wohl, M. J. A., Kuiken, D., \& Noels, K. A. (2006). Three ways to forgive: A numerically aided phenomenological study. British Journal of Social Psychology, 45, 547-561.

Yehuda, R., Bierer, L. M., Schmeidler J., Aferiat D. H., Breslau I., \& Dolan S. (2000). Low cortisol and risk for PTSD in adult offspring of holocaust survivors. American Journal of Psychiatry, 157, 1252-1259.

Yzerbyt, V., Dumont, M., Wigboldus, D., \& Gordijn, E. (2003). I feel for us: The impact of categorization and identification on emotions and action tendencies. British Journal of Social Psychology, 42, 533-549.

Zechmeister, J., Garcia, S., Romero, C., \& Vas, S. N. (2004). Don't apologize unless you mean it: A laboratory investigation of forgiveness and retaliation. Journal of Social and Clinical Psychology, 23, 532-564.

Received January 5, 2007

Revision accepted March 30, 2008 